\title{
The Oregon Declaration on Environmental Education
}

The annual meeting of the International Society for Environmental Education (ISEE), on 9th and 10th September 1986, in Eugene, Oregon, was the initiating event of a week-long conference involving environmental educators from all over the world. Addressing the theme 'Environmental Education: Transition to an Information Age', the conference examined implications for Environmental Education programmes and global application of information technologies in a period of rapid change. As a reflection of the recurring international environmental focus on 'thinking globally and acting locally', the conference was being co-sponsored by a number of international, regional, and local, organizations including:

- The North American Association for Environmental Education (NAEE)

- The Global Tomorrow Coalition (GTC)

- The Northwest Association for Environmental Studies (NWAES)

- The Environmental Education Association of Oregon (EEAO)

- The Solar Energy Association of Oregon (SEA of O)

- The Western Regional Environmental Education Council (WREEC)

The recent famine in Ethiopia, the gas leak at Bhopal, and the nuclear accident at Chernobyl, have drawn public concern and attention to the multiple threats to regions and to The Biosphere as a whole. The resultant story of human misery, environmental hazard, and ecological destruction, is being heightened and refocused.

It is time for educators to address the long-term ecological consequences of human economic development.
Short-term development gains must be seen in the context of long-term biospheral sensitivity. Development planning must simultaneously consider both protecting the life-support systems of the planet and economic development.

The nations of the world are becoming more socially and economically interdependent. Future survival will require international cooperation and harmony rather than competition and confrontation between the superpowers and developing nations. This will require the infusion of a strong environmental ethic into every aspect of science, education, business, and government. Only then can a fundamental restructuring of human and ecological development programmes occur.

Education will play an important role in the long-term resolution of environmental problems. To promote the cause of global environment education, the ISEE is organizing the global community of educators and establishing a communications network for mutual support and the exchange of information. In doing so, it is hoped that the global community of nations will be able to resolve environmental problems more efficiently and effectively than in the past, to promote ecologically sensitive human development.

The above Declaration was approved, on 10 September 1986, by the delegates of the Fourth Annual Meeting of the International Society for Environmental Education, at the University of Oregon, Eugene, Oregon, USA.

Craig B. Davis, Secretary-General of ISEE Director, School of Natural Resources Ohio State University Columbus

Ohio 43210, USA.

\section{The Human Response to Global Change: Programme on Planning and Preparedness}

It has been proposed that a new Programme be initiated, entitled the 'Human Response to Global Change', to examine the diverse and critical influences of human activities on the rapidly-altering face of the globe. The Programme will undertake to engage and support those who study, manage, or interpret, human activities on all scales-from the local to the global. It is envisaged that its 'research horizon' will take it through the decade of the 1990s and past the year 2001 .

\section{Initial Steps}

The Human Response to Global Change Programme took its cue from the escalating problems of physical or environmental change at the global level, and, in particular, as a response to the challenge put forward by the International Geosphere-Biosphere Programme known as 'Global Change'-a science-based international programme that is set to begin its operations in 1988 and also work through the next decade. The 'Global Change' Programme, as envisaged, will examine the characteristics of the physical changes that are now under way on the planet; but its mandate stops short of exploring in detail the human causes of, and responses to, those changes.

As a result, the Human Response to Global Change Programme was set in motion, first by an ad hoc Preparatory Group meeting, held in Toronto, Canada, on 11-13 June, 1987, at the invitation of the International Federation of Institutes for Advanced Study (IFIAS). The meeting was co-sponsored and supported by a number of international organizations, both governmental and nongovernmental, and involved the participation of concerned individuals and scientists of acknowledged expertise in the field.
The meeting determined that the Programme should be undertaken, and that it should stimulate and foster research into the human causes of - and responses to-the unique level of global change that is now occurring. The Programme would thus seek to understand the fundamental dynamics of human interactions with the global environment, both in order to understand the basic processes at work in altering the face of the planet, and also to diagnose and propose remedies that could help to achieve an improved human response. It was understood that the Programme would require the involvement, assistance, and support, of a world-wide array of interested partiesranging from concerned individuals to committed scientists, and from international agencies to local and regional research organizations-both 'on the ground and in the line-of-fire'.

To further these aims and this approach, the meeting in Toronto proposed the establishment of an Interim Steering Committee, a working Secretariat, and the creation of a network of interested parties for the Programme.

In the first instance, the Interim Steering Committee will be made up of representatives of the International Social Sciences Council (ISSC), the United Nations University (UNU), and IFIAS, to be followed by other invited representatives as required. This interim Steering Committee and its Secretariat have, as their initial tasks:

- the creation of a network of interested Programme participants;

-the identification of potential supporters and donors to the Programme;

-the preparation of provisional budgets, schedules, and initial task management; and 
- the promotion of the Programme in all appropriate jurisdictions and media.

In particular, the Interim Steering Committee is involved in the preparations for a formal International Symposium, scheduled for the Fall of 1988, and hosted by UNU in Tokyo, which will establish the Programme's main phase of operations.

\section{Current Activities}

Following the Toronto meeting, a Report of that meeting is being circulated where appropriate; and an extended Prospectus outlining the aims, objectives, administration, and provisional schedule, of the Human Response to Global Change Programme, has also been prepared for circulation (available on request from the undersigned).

In addition, a number of initial Working Groups are in the process of creation by IFIAS, in order to facilitate the development of 'leading themes' for the Programme. These Working Groups-some of which are required to undertake their activities preparatory to the full-scale adoption of the Human Response to Global Change Programme- include: a Working Group on Data Management (to liaise with the current initiative of the International Geographical Union on Global Data-Base Managment); a Working Group on the Analysis of Complex Systems; a Working Group on the 'Needs of the Most Vulnerable'; a Working Group on 'Global Risk Assessment'; and a Working Group on 'Global Environmental History'. These Groups are now being formed, and will probably be involved in the formulation of planning-documents and position-papers for the near future.

At the same time, funding is being sought for these and other activities through appropriate government, nongovernment, and private, sponsors. Further information on this most interesting new global initiative can be obtained in the first instance from the undersigned.

Peter Timmerman, Research Associate

International Federation of Institutes for Advanced Study 39 Spadina Road

Toronto

Ontario MSS 1 A4

Canada.

\section{Proposal to Establish an International Fund for Research on the Prevention or Mitigation of Major Accidents}

\section{Background}

Major accidents such as those at Flixborough, Seveso, Mexico City, Bhopal, Chernobyl, and the recent Rhine spill, have resulted in direct and indirect international repercussions, and in financial and economic impacts extending far beyond the immediate environment that was impacted by the disaster. As we have already seen, such accidents are just as likely to occur in industrialized as in newly industrializing countries. Moreover, in the future, the possibility of accidents greatly exceeding the international impact of those listed above have been predicted by experts working in the field.

During the past fifteen years we have come to recognize that those large-scale disasters are not due to 'acts of God', as some types of natural disasters are considered. Rather, they are the result of a series of multiple human and equipment failures over a period of time-resulting in a failurechain (sometimes exceeding 15 identifiable failures), which could have been prevented if the chain had been blocked or broken at some stage during its propagation. It is now recognized that all major accidents are preventable, but the question is: How can we identify a high-risk system a priori and implement prevention measures to block a failurechain leading to a major accident?

\section{Proposed Research}

Three levels of failure have been identified in all failurechains leading to a major accident, namely: equipment failures, human operator failures, and management-organizational system failures. Major accident investigations and the subsequent follow-up research have focused almost entirely on equipment and human operator failures, only minimal research having been carried out to date on management-organizational failures. Many equipment failures can be traced to human causes due to design, construction and/or maintenance, and testing failures. Moreover, recent studies have shown that, in most organizational systems, $80-85 \%$ of the failures are in the management and organizational elements of the system, while only $15-20 \%$ are due to so-called 'human error'.

With this new understanding we now recognize that much of the previous work in major accident investigation and prevention has been directed at only about $20 \%$ of the problem. Research work in equipment and human operator failures will continue to play a vital role in major accident prevention, but a new major research thrust is required in the area of management and organizational system failures.

This new approach to major accident prevention will be applicable to organizations in the industrial, nuclear, and hydro-energy, sectors; the defense and aerospace industries; to sea, air, road, and rail, transportation; and to any international, governmental, or private, organization seeking to prevent system failures and improve management-organizational performance. Consideration of the management-organizational system failures is not included in current risk assessment methodologies that are being applied by regulatory authorities and industrial organizations.

\section{World Bank Role in Major Accident Prevention}

Since 1984, the Bank's Office of Environmental and Scientific Affairs has played a leading international role in the application of current knowledge, the development of improved methodologies and techniques, and the provision of guidelines, manuals, and computer techniques, for major accident prevention, which have been well received in both the developed and still-developing countries. The Bank is currently co-sponsoring research, with assistance from the Danish Consultants Fund, on management and organizational factors for incorporation into a prototype Integrated Safety Audit System for Major Hazard Plants. However, this work needs to be substantially expanded in its scope and international perspective.

An outline of such a greatly-expanded research programme, designed to identify the critical managementorganizational factors in major accident prevention, is currently being developed with the assistance of international experts.

\section{Purpose and Organization of an International Fund}

The World Bank has served as an executing agency on a number of large international research efforts involving both developed and still-developing countries. The international scope of this project, and its urgency, require a similar coordinated and concentrated effort. An international expert committee would be selected to develop the research programme, ensure quality-control, and effect wide dissemination of the results. A donors' group would also be formed to provide oversight and financial support. A very small research management, coordinating, and implementing, team would operate out of the Bank. 